\title{
Examining The Internship Curriculum in Acquiring Teaching Abilities
}

\author{
Ahmad Reza Fatahian Kelisha Dorkhi ${ }^{1}$, Behrouz Shahmirzai ${ }^{2}$, Mahshad Khalife Soltani ${ }^{3}$ \\ Milad Shams ${ }^{4}$ \\ ${ }^{1}$ BA Student in Educational Sciences, Shahid Ayat Najafabad University of Farhangian. \\ ${ }^{2}$ BA Student in Educational Sciences, Shahid Ayat Najafabad University of Farhangian. \\ ${ }^{3}$ BA Student in Educational Sciences, Fatemeh Al-Zahra Campus Univesity of Farhangian in Isfahan. \\ ${ }^{4}$ BA Student in Educational Sciences, Shahid Ayat Najafabad University of Farhangian.
}

ARTICLE INFO

Keywords:

Internship, Teacher,

Competence, Ability

\begin{abstract}
Considering the importance of experience in learning each topic and its importance in becoming professional actualize knowledge, today, a particular focus is done on the more precise formation of internship courses during education. One of the most sensitive of these educational courses is related to the teacher training. Hence, in this article, titled the study of the internship curriculum in acquiring the teaching abilities, we express the characteristics of the teacher required from different sources and the internship needs in all professions as well as the importance of this curriculum in teacher's training and the relationship of this curriculum in the acquisition of teaching competences and we study the implementation of this curriculum at the University of Farhangian. As well as we compare the standards of this curriculum in the teacher training of advanced countries and study the shortcomings and positive points, as well as the view of the students of Shahid Ayat Najaf Abad Center (Farhangian University) about this curriculum. The result of the study shows that this curriculum is effective in acquiring the teaching competencies, but it requires reforms in line with the criteria of update knowledge and the national transformation document to overlap the desired criteria.
\end{abstract}

\section{Introduction}

All of us in our lives have learned skills and internship related or non-related to the field of study. Now, this internship can be voluntary or involuntary. "We are placed in that unwanted." But we all know nothing to learn is informative and lasting like experiencing, and we all know that experiencing in everything is essential to make a raw person mature, and this necessity for a professional such as teaching which generates a generation in the future is important and does not leave any error or mistake. Therefore, designing and having a complete, comprehensive and precise curriculum for the achievement of student teachers to the desired and expected level of the basic educational transformation document as well as the criteria matched on update knowledge and effective education system will also increase its necessity. Whatever increased the importance of this research and attracted us to this issue is that the research on internship at Farhangian

* Corresponding Author E-Mail Address: ahmad04635r@gmail.com 
University not examined in detailed the adaptation of this curriculum for realizing criteria of professional teacher in terms of fundamental transformation document. Also no study has investigated the similarity and difference with internship in teacher training systems in advanced countries and sought to modify this curriculum in teacher training to achieve a complete curriculum that combines the features of advanced teacher training systems and the fundamental transformation document of education. Therefore, in this article, we have studied this curriculum at Farhangian University in order to eliminate the shortcomings and adapt it to realize the stated criteria. Finally, based on a case study carried out in an article on this regard, we examine the shortcomings of the positive points and the proposals of the students of Shahid Ayat Najaf Abad University of Farhangian in 2012. Then, we will be familiar with competences of a teacher from the perspective of different sources, to find out what is expected from an internship course for educated teachers, and what features should have to fulfill these expectations.

\section{Features of teacher with competence:}

Teaching competences are a set of cognitions, attitudes and skills that teacher by achieving them can help the physical, intellectual, emotional, social and spiritual skills of learners. These competencies can be classified into three cognitive, emotional and skillful areas. Cognitive competencies are a set of knowledge and mental skills that enables the teacher to identify and analyze questions and issues related to education.

The emotional competences is the teacher's tendencies and interests to issues related to education, and the skill competencies are related to teacher's skills and abilities in the learning process. Of triple competences, the competence of affecting the student is obtained (Maleki, 2005) it has classified the capabilities of the teachers in three areas of professional knowledge, professional practice, and professional commitment (Huntley, 2008). Expected criteria from a professional teacher can also be derived from the educational system standards of advanced countries in education. It is worth noting that these countries have definitely considered a more appropriate approach and have studied more extensive researches in these fields that are in such a position of educational systems, therefore, we study these criteria in the educational system of the United States, England and Singapore which are the most advanced countries in the field of education.

\section{Teacher competences from the perspective of fundamental transformation document of education}

- Having moral virtues and professional competencies with unified monotheistic identity based on Islamic criteria

- Based on an accountable, participatory management approach

- Relying on the education elements and benefit from the capacity of contributing and effective factors and based on beneficiaries' engagement emphasizing coaches, students and families.

- Having the benefit of educational technology at the standard level; Given the range of resources and learning media (National Information and Communication Network)

- Having the decision-making capacity for the formal public education system

- Effective interaction with mosques and other institutions, religious centers and local centers such as cultural centers, public libraries, and having continuous and effective relation with religious scholars and experts. 
- Having an effective link with community issues and issues at the local, regional and national scale with active participation in social life (the fundamental transformation document of education)

A teacher with competence includes the features we described, but we must know that these competences must be obtained in the pre-employment and educational periods of teacher training, and the necessity of this issue is because the course of teaching that includes time of development and the formation of future generation is not a place for gaining experience, testing, and error. The need to prevent educational damage and the generation under training has great importance, which makes important training courses before entering the education system. Hence, we express the necessities to achieve harms and ways of reforming, as well as aligning with the best practices of this very important curriculum, which is the most important curriculum for learning, evaluating and improving the teacher's abilities.

\section{Necessity of internship}

Higher education of any country, as much as is stronger in terms of theoretical (both classical and modern) training, it cannot yet be successful in providing economic and industrial growth. This explains the extension of the range of education and experience from the actual work environment. Currently, that the period of degree orientation is passed, and the community, industry and university should provide the required fields for gaining useful experience for students. The admission of trainees from universities, as an effort to heal the gap between the formal education system and what is going on in the industry, "the realm of action" is done to restore part of the educational vacuum, familiarity with the word and occupations in the industry, to develop the attitude of students towards the industrial system.

Knowledge of most universities and higher education institutions to what is in industry will be able them to develop the expansion of the scope of information and skills and career identification. Additionally, close contact of trainee with industry will provide opportunities for the use of academic findings and knowledge in practical situations, and will provide opportunities for aptitude of trainees.

Students' internship is done according to the most common form of internship, I.e, training in the professional environment and education in the material environment, in order to be able to complete missing circles in the university education system by transferring education to the professional environment and utilizing the knowledge due to the work environment (Dalin site, 2016).

\section{Internship goal}

Students' familiarity with practical and executive issues and workshop issues as closely as possible to understand the chance of matching learning with action and to try to remove shortcomings and possible defects.

Dealing with workshop, labor, and social issues and faced with objective realities

Understanding the importance of scientific skills and the relationship between them and the way of cooperating owners of different skills and specializations and the role of each one in advancing tasks.

Understanding the role of the workshop and the need for sufficient mastery to practical and executive tasks

Creating an opportunity to flourish students' creativity and provide better ways to create operations 
Transferring academic and research findings from university to industry, and in other words, students' internship is between university and industry, provided that students have strong backgrounds and new word for industry workers.

Mehrmohammadi, in an interview on the website of the Supreme Council of the Islamic Revolution, says about internship:

Question: I think several days ago, you pointed out that your students are ready for attending schools for internship.

Please propose a brief overview of the work process of the University of Farhangian.

Now we have reached a stage where students passed in 2012 should go to the internship part, the first period that we took student, and based on the program we predicted, students have to go to school for four terms for internship and this is the turning point of the curriculum of teacher training; As well as professional education programs in any other area, such as medicine, law, etc., in the field of education, professional elements that the teacher need to work in objective and practical environments in the field, which is the school; So, as long as this link is not established with the school, the realization of the goals of professional training i.e teacher training that has the competencies required to deal with learning problems, educational issues, and the like, can be achieved in a very limited way. Realization of professional competencies in the teacher training entails this stage of internship which is a stage for obtaining field and clinical experience; therefore, I believe that we are entering a turning point in our programs at the University of Farhangian. We have organized to provide the new generation of teachers using the best teachers working in education who receive the necessary training from the University of Farhangian and receive a certificate of teacher competence-internship guidance. I hope that student-teachers to be achieved the goals within the framework of the programs for 4 terms predicted. This is an extremely dangerous and critical step (the site of the Supreme Council of the Revolution, 2016).

\section{The importance of internship curriculum at the University of Farhangian The position of internship in education}

Knowing is just irrigation, to grow ability.

Knowing is not ability; but ability can be also knowing, because every good thing to do must inevitably be done by ability. The vice versa of this issue is not fixed. So much knowledge cannot be taken to the field or lead to do something, in which all knowledge, or even some knowledge, has been used. All abilities are from experiential and functional categories. The loud voice of every action is arisen always from the ability and acting; therefore, the weakness of many teachers in their professional skills is not merely from their ignorance, but simply because of their failure. The short text below is a slice of proof of the subject that is believed in teacher training and placed internship curriculum in the highest position.

\section{The importance of internship curriculum}

Internship curriculum is one of the main indicators of new and improved teacher training. It plays an essential role both in pre-service training and in-service teacher training. The main reason for this is that the internship curriculum is "practicing practical and executing skills" that can shape, develop, and guide the professional personality of teachers to their professionalism or "professional artists." This lesson can foster, empower individual empowerments of teachers, and go so far as to be able to use the most productive ways and possible strategies in the most difficult working conditions. 
The formation of professional characters can be interpreted as a skill creation rule in practice. A simple law that governs every profession, for example, if all the equipment to be provided, a big budget be used, everyone be mobilized and a modern and equipped hospital be prepared until the doctor and therapist not to be provided for different parts of it, as if the hospital is not established, but if only the doctor is provided; Provision of equipment and preparations can take place one after the other because skilled craftsmen can build everything and create and exploit the minimum facilities. In the past, in teacher training, often investigating this important principle was ignored, with the traditional belief that more familiarity of teacher about knowledge and information about the subject is more important than teaching methods. In other words, they considered the work of the teacher as a blessing, not a professional to learn.

As if the selectors were originally created for this profession and no longer need to be made. Professor Gig writes: Everybody knows that teacher training in his long history has enjoyed a low status. It is quite possible to find documentation of this tedious situation in the nineteenth and twenty centuries. Much of the teacher training curriculum is dedicated to the teaching competence that teachers need to know. Therefore, in today's teacher training, learning professional skills has the equal value and credibility not only with knowledge and information of teacher, but also according to the belief of many educators has a superior position and has been raised in the category of "art and artistic". For this reason, the time and practice of internship and practicing of teachers (internship) has increased. The internship of teachers is in the line of engineers, physicians, aerospace, artists of seventh art internships and other accredited executive jobs which considered professional creativity and artistic, and a variety of new techniques and initiatives and innovations have been created. Not only the neglecting and non-significance of this lesson are considered as the inadequacies of the teacher training system, but the reform of the ineffectual past practices has always been considered. All types of internship practices are taught in the teacher training centers and after the pilot will be investigated and criticized to refine their maladaptation. Internship curriculum in teacher training has a great status as entered other major elements of teacher training or aligned them with its own criteria. The internship curriculum in education is so important that it is the only fading element of the gap between knowing and ability. Teacher without competence refers to someone who has not trained enough in teaching skills or has been deprived of such practical experience (Rauf, 2007).

In addition to this, we prove the need for internship lesson with the research done in the world's educational systems: The book ("Thinking about the evolution of education"), which was the product of 1980 and 1981 congresses at UNESCO, referred the evolution of the teacher's role in teacher training curriculums. According to the Universal Declaration of "Education for All", which was issued in 1980 by the World Conference on Education at UNESCO, one of the most important infrastructures in this field is the improvement of teacher training (Rauf, 2000).

Also, Rosamaryatours, UNICEF Senior Education Advisor, in his book, considers improving the quality of education depending on the professional competencies of teachers, and believes that change in the education system of future teachers is necessary. In his research on the study of the global movement for improving the teacher training (2000), Rauf also proposed a selection of the major projects that implemented by industrialized and non-industrialized countries under their own needs and conditions and facilities in teacher training in 1980-1994. He believes that all countries have found the necessity of attention to change and rehabilitate teacher training programs and follow up change programs. A comparative study in 1999 Asia Pacific Economic Cooperation (APEC) in France, Germany, New Zealand, Hong Kong, China, Japan, and Canada regarding education and, in particular, teacher training with regard to goals, selection, content of teacher 
training program and preparing teachers shows that teacher training is an essential element in the development of education. Accordingly, in these countries, the duration of training and teachers and the duration of practical training (internship) is increasing (Kub, 1999). Al-Nouravilich and Fernand and Rimmerz in their study in 2000 "The Professional Growth of Teachers as Learners during Lives, Patterns, Exercises, and Factors Affecting It," compared teachers' education system and their professional development in 15 Countries: England, Germany, the Netherlands, Spain, Sweden, Portugal, Ukraine, China, Malaysia, Singapore, Australia, Israel, North America and Canada. The results of this study showed that professional development of teachers should be considered as a process that began from pre-service period and contains life-long and their professional development should be systematically designed, supported and budgeted and investgated. The system should enhance the effectiveness of teachers. The pre-service plans for teachers should be based on the knowledge of education, along with practical exercises (Malaiy Nejad \& Zakavati, 2006).

To what extent the internship curriculum at the University of Farhangian, considering its features, shortcomings and its positive aspects, affects the formation of a professional teacher.

The internship curriculum at the University of Farhangian, due to their comparative study in countries with advanced educational systems such as Britain, Japan, France and Germany have differences and similarities that we examine them:

\section{Similarities}

Most countries have placed the increase of the practical programs and the balance and relation between theoretical and practical training on the agenda of the teacher training curriculum. These countries, while emphasizing the theoretical curriculum and understanding the materials, believe that the curriculums should be designed in such a way that the students- teachers are able to pass practical curriculums simultaneously with these curriculum and be able to have theoretical concepts in action and class. All countries have considered curriculums as teaching practice for teacher-student attendance in the classroom and school, and they consider it one of the most essential programs of teacher training and design their own plans based on it and seek to increase the length of the course and these countries consider to have a closer relationship between schools and universities in order to effective implement these courses. Guidance teachers in these countries are selected from the most qualified school teachers and have adequate self-awareness to their duties.

\section{Differences}

Given the length of the course and standardization, there are differences between the number of curriculums in the countries, the issues and how to balance between practical and theoretical curriculums. In England, curriculums for the acquisition of skills for the registration and maintenance of student activities and the provision of regular quantitative and qualitative reports to parents, identifying the objectives and the way of assessment and reporting, and the ability to regulate teaching activities are provided. Another difference is the increase in students' practical programs, which is to create a graduate course for taking the degree of professional skills. Also, student- teachers should, after the end of the course, spend a one-year course that is most practical to be fully prepared for practical teaching in the school. In England and France, this course is 
planned during the curriculum of teacher training, so that student teachers can exchange their experiences in classroom with their professors and their classmates. In fact, it is planned to be integrated with other curriculums. In France, the principles of scientific and practical education are entirely provided in the education curriculum, and education is based on the teaching of scientific and practical principles in teacher training courses. Generally, one-third time of training students is dedicated to pass internship courses and analyze teaching materials. The internship course of the students is started from the second year and is conducted during the course and the final eight weeks of practical training of these students are officially carried out while these students accept responsibility for a post. In this country, due to the short duration of the course (1 year) in the first year, strengthening and consolidating their practical skills and increasing their background knowledge is investigated. In the second year that participants passed the entrance examination, teaching the skills and professional skills of teaching will be investigated. It is tried to student teachers often do practical things and use their knowledge to increase these skills. In Germany, students in teacher training courses during their education practice the learned materials. The practical activities of these courses take place in two parts during the semester at the end and after the semester. The practical stage of teacher training courses in this country lasts nine years, during which students attend various seminars. In Japan, educational internship plays an important role in the teacher training curriculum. In this country, it is required that students practice learned materials through internships. In Japan, each curriculum of teaching practice is equivalent to one week of teaching in schools (Samiei Zafarqandi, Morteza, 2011).

Iran: By establishing Farhangian University in 2011, the teacher training and internship approach based on the principles and guidelines contained in the document of the development of education, as well as the theoretical fundamentals of fundamental change in the education of the Islamic Republic of Iran, more serious moves and activities to utilize principles in documents was begun. In this rethinking and redesigning, internship plays a prominent role in building the competencies as well as more than ever in interconnection of theoretical foundations with practical capabilities in the positive and effective interaction between the university and the school. In this regard, the principle of using and establishing internship system became important. The program has been set up for four continuing education semester, for each course or half -year of internship, two curriculums is dedicated, in which, in fact, students will have eight internship curriculums per week in their bachelor's degree, the titles of which are as follows:

Internship 1: Reflective observation and teacher training. Includes two educational units of 128 hours with the prerequisite of educational psychology, professional development, generalities of methods and teaching techniques

Internship 2: Participation in teaching and learning activities. Includes two training units in 213 hours with pre-requisite of internship 2

Internship 3: Experimental and individual research action teaching

Internship 4: Independent study and teaching

\section{Common Characteristics in Advanced Systems of Education in the World}

What we intend to state to develop the internship curriculum at the University of Farhangian is also obtained of the adaptive study of the curriculum, especially internship in the education system of the leading education countries. By examining the teacher education system in countries such as Britain, France, Japan, Malaysia, South Korea and Finland, we concluded that the teachers' education system in these countries has a very high student practical work hours. For example, in France, from the first year of study, 1/4 of the curriculum or time devoted is related to practical 
curriculums. Through a comparative study of the South Korean education system, we witnessed the passing of very large practical units of the teacher at various centers and to the end of his career. (Hakimzadeh and Amrullahi, 2014).

Therefore, in examining these teacher training systems in these countries, what was common and needed for the teacher's practical training is the increase of practical curriculums along with the supervision and evaluation of professors, as well as the practical assessment of the individual in the real class, the theoretical teaching with practical training except unrelated theoretical curriculums, working with up-to-date training tools and training the latest methods of classroom management, educational management and, most important of all, their implementation and pathology, in addition to monitoring and evaluation, and the subsequent improvement of teaching skills throughout the occupation, which is highly effective and efficient. For example, in South Korea, a teacher during his / her internship course in education system examines all the teaching abilities, and in the case of lack of these competencies, they will be sent to six-month courses of study (Sha'bani, 2004).

Also, referring to the results of a case study in one of our articles, we will investigate question 2 in questionnaire on the extent of effectiveness of internship in success of graduate students (novice teachers).

\section{Could the four internship curriculums offered at the University of Farhangian be effective in success of novice teachers in teaching social studies?}

The average score obtained for this question was obtained through questions 4, 5, 6, and 7 of the questionnaire, 4.21 with a standard deviation of 1.12 and variance 2.25 which indicates that the materials about social studies courses at the time of the student in the form of internship 1, 2, 3, and 4 by teachers and masters of internship at schools provide useful experiences for students that have been used today. Among these sub-queries, the highest score is related to question 7, which novice teachers have considered their most useful experience in internship 4 which they have taught directly "under the guidance of the supervisor" (Sharifi, Fattahian, 2017)

The final result according to the comprehensive principles explained in the fundamental transformation document of education

Therefore, by following and implementing the fundamental transformation document in the field of education and teacher training in the country, the allocation of budget and justification, it can be reduced all the deficiencies in the important period of student-teacher internship during pathology and eventually eliminated. Thus we describe what is in the fundamental document of education of the country on teacher training and the acquisition of professional skills and what expects of a teacher.

According to the fundamental transformation document of education that was approved by the Supreme Council of the Cultural Revolution in 2011, in principle 11, the necessity of a change in the field of internship is as follows: the re-engineering of policies and the re-establishment of the principles governing the education curriculum, with emphasis on internship and conformity of the level of professional competence of teachers at the national and international level, with the requirements of the curriculum model in the education system, and the design of appropriate policies to promote the methods of attracting, educating and retaining teachers in education, which 5 strategies are presented to implement this principle. 
- Establishment of the national system of teacher training and the establishment of University of Farhangian with a professional and specialized education approach of training-centered by the Ministry of Education in cooperation with relevant organizations.

- Designing and enhancing teachers' professional education system in education, emphasizing maintaining student teachers' interaction with schools and scientific and research institutions during this period and providing the opportunity to get real experiences from the classroom and educational environments.

- Creating a teacher qualification assessment system including moral, belief, revolutionary, professional and specialized competencies, and assessment in line with the principles and objectives of the strategic transformation document

- Developing the field of research and increasing the individual and collective professional capacities among teachers, exchanging experiences and achievements at the local and national level, and creating continuing retraining scientific and research opportunities and holding superior teaching festivals and allocating specific credits for teachers' research activities.

- Planning for student teachers' internship along with teacher training and reviewing new views of education

However, in the new internship program of Iran, Farhangian universities, unlike the principles in fundamental transformation document, merely design an internship folder, regardless of the increasing professional skills of student teachers, while students spend their entire internship time for writing daily reports and eventually compiling a final report. In this way, not only will they not receive a vocational education and experience from the help of student teachers, but the plurality of journal writing will create a negative attitude toward student teachers.

In this way, the plurality of writing report will create a negative attitude towards the student teachers. Also, the low proportion in this practical unit is relatively low in comparison with the total units in advanced countries of the world in the field of education, and the supervision of professors on the student in the real situation of the internship is low, which prevents solving problems, paying attention to the correct training and enjoyment of position.

But in general, we consider internship curriculum to realize the ability to increase teaching competence in students based on relative adaptation to the goals of the fundamental transformation document, as well as the student's own ideas and the adaptation to some of the internship programs in advanced countries effective.

* Therefore, it is recommended to increase the efficiency of this curriculum:

* Increasing the hours of this curriculum

* Increasing the number of internship professors and reducing students under its supervision

* The supervision of the professors on the student is in the actual situation of direct internship along with expressing points and removing problems.

* Internship to be done in accordance with the update teaching of the world and using tools and new ways, also the training must be under the supervision of professors and his direct supervision, because teachers in the class are teachers trained or accustomed with the old and inefficient system and this is something undeniable; the existence of an inappropriate method in the classroom causes to the modeling or inappropriate effects of education and training in the student.

\section{References}


Amrullah, Omid and Hakimzadeh, Rezvan, 2014, Quarterly Journal of Higher Education Curriculum Studies, No. 9spring.

Cobb velma (1999). An international comparision of teacher education ericdigest. Eric clearing house on teachingand teacher education Washington dc.

Dalin website, 2016, http://ladin.ir/other

Huntly, Helen (2008) “teachers' Work: Beginning Teaches' Conceptions OF Competence”, The Australian Educational Researcher, Vol.

Malaiy Nejad Ali, Zakavati Azam, 2006, Comparative Study of the Education Curriculum System in the United Kingdom, Japan, Educational Innovation Quarterly, No. 26, Summer 2008.

Maleki, Hossein, 2005, Teaching Professional Competences, Tehran, School Publishings.

Mehmohammadi, Mahmoud, 2014, website of the Supreme Council of the Revolution. http://sccr.ir/pages/?current=news\&gid=34\&sel $=859670$

Rauf, Ali, 2000. World movement of teacher training, Research Institute of studies of Education. Rauf, Ali, 2007, Teacher training and Internship, Tehran: Ravan Publication.

Samiei Zafarqandi, Morteza, 2011, Teacher training in Iran and the World, Teacher Development, No. 191

Sha'bani, Zahra, 2004, a Comparative Study of the Education Program in Iran and Several Countries, Journal of Education, No. 79, autumn.

Sharifi Rasool, Fattahian Kelisha Dorkhi, Ahmad Reza, 2017, An Investigation of Effective Factors on the Efficiency of Novice Teachers to Teach Social Studies, the National Conference on Teacher Education, the Civilika Database

The Strategic Document of the Transformation of the Official and Public Education System of the Islamic Republic of Iran, 2011, Supreme Council of the Cultural Revolution. 